\title{
Sucralfate - Oxetacain Suspension in Management of Persistent Gastroenteritis of Varied Origin
}

\author{
Dr Avinash Shankar ${ }^{1}$, Dr Amresh Shankar ${ }^{2}$, Dr Anuradha Shankar ${ }^{3}$ \\ ${ }^{1} M B B S(M G I M S) ; M D($ Internal Medicine);DNB(E\&M);PhD, Post graduate in Edocrinology \& Metabolism \\ (AIIMS-Delhi), Chairman, National Institute of Health \& Research, Warisaliganj (Nawada), 805130, Bihar, \\ India \\ ${ }^{2}$ BAMS (BRABU); MBA (HA), Bihar state Health Services, Govt of Bihar, Patna \\ ${ }^{3} B A M S(B R A B U)$, Director, Centre For Indigenous Medicine \& Research, National Institute, Of Health \& \\ Research, Warisaliganj (Nawada),805130,Bihar, India
}

*Corresponding Author: Avinash Shankar, MBBS(MGIMS);MD(Internal Medicine); DNB (E\&M); PhD, Post graduate in Edocrinology \& Metabolism (AIIMS-Delhi), Chairman, National Institute of Health \& Research, Warisaliganj (Nawada), 805130, Bihar, India

\begin{abstract}
Present therapeutics in vogue not only fails to secure cure but persistence of diarrhea even with present therapeutics usually turns fatal or present with sequel like - mucous colitis, UTI, vague abdominal pain and heaviness in the abdomen, But present study affirms the clinical supremacy of sucralfate-oxetacain composite ( $S F T-O)$ as adjuvant with continuing therapeutics in early resolution of presenting sign and symptoms without any drug or disease related sequel with $100 \%$ compliance in both children and elders.
\end{abstract}

\section{INTRODUCTION}

Persistent gastroenteritis of varied origin either in children or adult poses life threaten due to loss of fluid and electrolyte loss non responsive to conventional anti diarrhea agent ,fluid and electrolyte supplementation and other adjuvant drugs due to continued provocation of fluid and electrolyte transport in the gut by the toxin.

Hence a study was planned to evaluate a cyto protective and local anesthetic combination as an adjuvant in gastroenteritis management at RA. Hospital \& Research Center, Warisaliganj (Nawada), Bihar, India.

\section{MATERial AND Method}

\subsection{Design of the Study}

Comparative clinical study was done to asses the clinical efficacy and safety profile of the cyto protective and local anaesthatic combination as an adjuvant in persistent gastroenteritis non responsive to conventional therapeutics.

\subsection{Patients}

Patients of gastroenteritis non responsive to conventional therapeutics attending at RA. Hospital \& Research Centre, Warisaliganj (Nawada) with following complaints were included in the study while patients with other associated diseases been excluded.

\subsection{Method}

Parent of the patient or patients were thoroughly interrogated for their presenting complaints i.e.consistency and frequency of stool, frequency of vomiting, nausea ,passage of urine and its frequency, drugs consumed and assessed clinically thoroughly for type of diarrhea, status of dehydration, renal status and other vital statistics.

Selected patients were thoroughly investigated for serum electrolyte, basic hematological, hepatic and renal status to adjudge the safety profile of the adjuvant drug. 
Patient's stool was examined to ascertain the causative pathogens and urine for super infection.

\subsection{Drug}

Selected patients were categorized in two groups for comparative evaluation and advocated -

Group A : Conventional therapeutics and fluid and electrolyte replacement.

Group B : Conventional therapeutics and fluid electrolyte replacement and Cytoprotective -local anesthetic combination SUCRALFATE-OXETACAINE (SFT-O SUSPENSION)

$\begin{array}{ll}\text { Dose schedule: Adjuvant trial drug been adm } \\ \text { Adult } & : 5 \mathrm{ml} \text { every } 6 \text { hours } \\ \text { Children } & : 2.5 \mathrm{ml} \text { every } 6 \text { hours } \\ \text { Infant } & : 0.5 \mathrm{ml}-1 \mathrm{ml} \text { every } 6 \text { hours. }\end{array}$

Fluid replacement is $100 \mathrm{ml} / \mathrm{kg}$ in schedule of $30 \%$ in first 30 minutes, $30 \%$ in 1 hour and rest $40 \%$ in 2 hours while electrolyte supplementation is done as per serum electrolyte status.

Selected patients were observed for -

- Nausea and frequency of vomiting

- Consistency and frequency of stool

- Abdominal distention, pain and cramps

Post therapy sequel can be assessed by-

- Constipation

- Mucous colitis

- Persistent pyrexia suggestive of UTI

- Prolapse rectum

Safety profile is assessed by estimating serum electrolyte, hepatic function hematological status, renal function test and urine culture and sensitivity

\section{OBSERVATION}

Among 1282 selected patients $7 \%$ were infants $(<1$ year), $27 \%$ were children $(<15$ years) while $66 \%$ were adult out of which $15 \%$ were of age $>35$ years. Sex wise distribution of patient is 11:9 $(55 \%$ male and $45 \%$ female).

Table1. Distribution of patients as per age and sex

\begin{tabular}{|l|l|l|l|}
\hline \multirow{2}{*}{$\begin{array}{l}\text { Age group } \\
\text { in year) }\end{array}$} & Number of patients & \multicolumn{2}{|l|}{} \\
\cline { 2 - 4 } & Male & Female & Total \\
\hline$<1$ & 48 & 38 & 86 \\
\hline $1-5$ & 62 & 42 & 104 \\
\hline $5-10$ & 64 & 51 & 115 \\
\hline $10-15$ & 70 & 60 & 130 \\
\hline $15-20$ & 88 & 67 & 155 \\
\hline $20-25$ & 92 & 74 & 166 \\
\hline $25-30$ & 86 & 67 & 153 \\
\hline $30-35$ & 98 & 77 & 175 \\
\hline$>35$ & 101 & 97 & 198 \\
\hline & 709 & 573 & 1282 \\
\hline
\end{tabular}




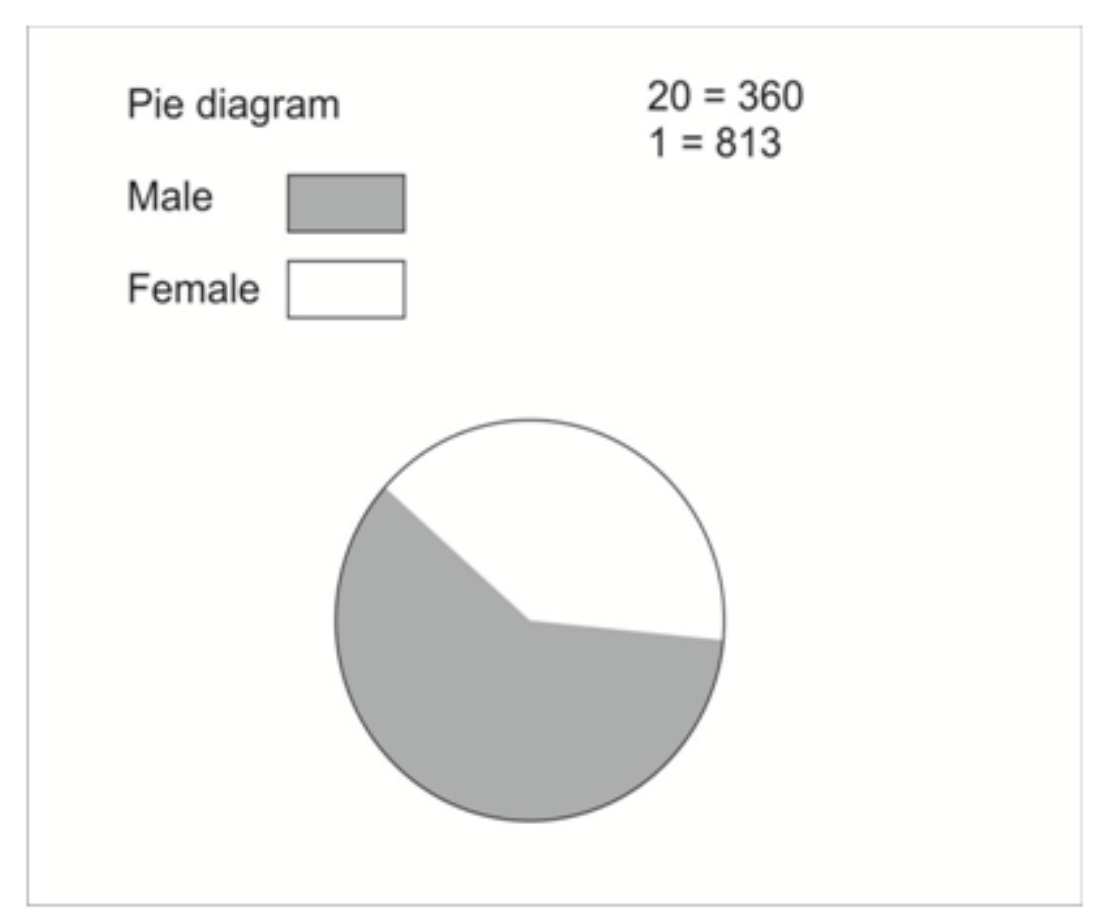

Pie diagram showing male -female composition

Majority patients presented with complaints of persistent vomiting and watery lose motion inspite of conventional therapeutics while 436(34\%), 532(41\%) and 384(30\%) presented with abdominal distension, abdominal colic and passage of round worm per oral or per rectal respectively.

Table2. Distribution of patients as per their presenting symptom

\begin{tabular}{|l|l|}
\hline Presenting complaints & Number of patients \\
\hline Persistent watery lose motion & 1282 \\
\hline Persistent vomiting & 1282 \\
\hline Abdominal distention & 436 \\
\hline Abdominal colic & 532 \\
\hline Passage of round worm per oral/rectum & 384 \\
\hline
\end{tabular}

Out of all $48 \%, 31 \%$ and $21 \%$ were of dehydration status grade I, grade II and grade III

Table3. Organism isolated on stool examination

\begin{tabular}{|l|l|}
\hline Organism isolated & Number of patients \\
\hline Non specific (No organism) & 632 \\
\hline V. Cholera & 336 \\
\hline Salmonella typhii & 314 \\
\hline Protozoa & 704 \\
\hline Helminth ova & 584 \\
\hline
\end{tabular}

$49 \%$ patient'sstool reveals absence of pathogens while $27 \%$ and $24 \%$ reveals presence of V.Cholerae and Salmonella respectively. In addition $55 \%$ and $46 \%$ patients revealed presence of associated protozoa and helminthes.

Table4. Distribution of patients as per their dehydration status

\begin{tabular}{|l|l|}
\hline Dehydration state & Number of patients \\
\hline Grade I & 612 \\
\hline Grade II & 398 \\
\hline Grade III & 272 \\
\hline
\end{tabular}

400( 62\%) patients of trial group had change in consistency of stool by 12 hours while only 30(5\%) patients of control group by 24 hours.200(31\%) patients of trial group had formed stool by 30 hours while only 12(2\%) of control group had formed stool by 48 hours. All the patients of trial group had formed stool by 72 hours of therapy while only $75(12 \%)$ patients had formed stool by 72 hours. 


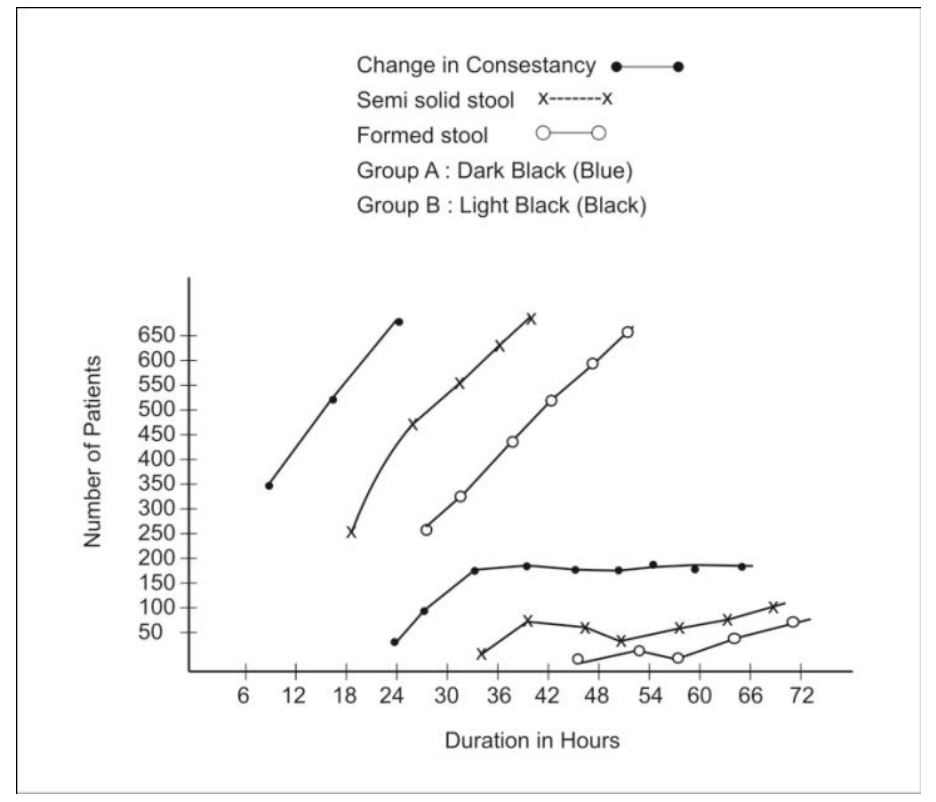

Graph showing change in consistency of stool in two groups

Average time required for decline in frequency of stool in trial and control group is 7-9 hours and 2448 hours respectively.

No patients of trial group show decline in hydration status while 321 patient of control group had decline in hydration status.

Post therapy stool examination shows absence of causative pathogens in all the trial group patients while only $53 \%$ patients of control group , $47 \%$ control group shows persistence of causative pathogen and $17 \%$ of control group show fungal super infection.

Post therapy culture and sensitivity of urine of patients presenting with pyrexia reveals no growth in trial group cases while 13\% of control group shows growth of significant colonies of Escherichia coli.

Post therapy assessment of hepatic function shows serum bilirubin <1mg in $98 \%$ and $70 \%$ of trial and control group patients while $5 \%$ and $20 \%$ of trial and control group patient show serum bilirubin $>1 \mathrm{mg}$ but $<2 \mathrm{mg}$,though $10 \%$ of control group patients show serum bilirubin $>2 \mathrm{mg} \%$.

192(30\%) patients of control group show altered hepatic function marked by raised serum bilirubin and other hepatic functions while 62 patients of control group show markedly raised serum bilirubin i.e.- $>2 \mathrm{mg} \%$

As per renal status 04 patients of control group show blood urea $>30 \mathrm{mg} \%$ and 02 patients of control group presnt with albuminuria while non of trial group had any alteration in renal function parameter.

$67 \%$ patients of trail group show improved hemoglobin while $28 \%$ patients of control group show decline in basic hemoglobin status.

In addition post therapy complaints like nausea, vomiting, fever, mucous colitis, abdominal pain and heaviness in the abdomen was completely absent among the trial group patient while common in control group patients.

Table5. Outcome of the study

\begin{tabular}{|l|l|l|}
\hline Particulars & Remarks \\
\hline & Group A & Group B \\
\hline Time required to decline & & \\
\hline In frequency of stool & $7-9$ hours & $24-48$ hours \\
\hline Hydration status: & & \\
\hline Decline & None & 321 \\
\hline Maintained & 219 & 320 \\
\hline Improved & 422 & - \\
\hline Status of stool after 72 hrs therapy: & & \\
\hline
\end{tabular}




\begin{tabular}{|c|c|c|}
\hline Absence of pathogen & 641 & 342 \\
\hline Presence of pathogen & None & 299 \\
\hline Super infection & None & 112 \\
\hline \multicolumn{3}{|l|}{ Status of urine: } \\
\hline Positive culture & None & 086 \\
\hline No growth & 641 & 555 \\
\hline \multicolumn{3}{|l|}{ Hepatic status: } \\
\hline \multicolumn{3}{|l|}{ Serum bilirubin } \\
\hline$<1 \mathrm{mg}$ & 609 & 449 \\
\hline$<2 \mathrm{mg}$ & 032 & 130 \\
\hline$>2 \mathrm{mg}$ & None & 062 \\
\hline \multicolumn{3}{|l|}{ SGOT: } \\
\hline$>35 \mathrm{IU}$ & None & 192 \\
\hline$<35 \mathrm{IU}$ & 641 & 449 \\
\hline \multicolumn{3}{|l|}{ Renal status: } \\
\hline \multicolumn{3}{|l|}{ Blood urea: } \\
\hline$<30 \mathrm{mg}$ & 641 & 004 \\
\hline$>30 \mathrm{mg}$ & None & 637 \\
\hline \multicolumn{3}{|l|}{ Serum creatinine: } \\
\hline$<1.5 \mathrm{mg}$ & 641 & 630 \\
\hline$>1.5 \mathrm{mg}$ & None & 011 \\
\hline \multicolumn{3}{|l|}{ Albuminuria } \\
\hline Absent & 641 & 630 \\
\hline Present & None & 011 \\
\hline \multicolumn{3}{|l|}{ Hematological status: } \\
\hline \multicolumn{3}{|l|}{ Hemoglobin : } \\
\hline Declined & None & 178 \\
\hline Improved & 432 & - \\
\hline Maintained & 209 & 463 \\
\hline
\end{tabular}

Table6. Distribution of patients as per their post therapy presentation

\begin{tabular}{|l|l|l|}
\hline Particulars & Number of patients \\
\hline & Group A & Group B \\
\hline Nausea & None & 146 \\
\hline Vomiting & None & 013 \\
\hline Formed stool & All & 123 \\
\hline Mucous colitis & None & 212 \\
\hline Fever & None & 312 \\
\hline Abdominal pain & None & 292 \\
\hline Heaviness in the abdomen & None & 321 \\
\hline
\end{tabular}

\section{DISCUSSION}

Persistent diarrhea and vomiting are common presentation in rural area in spite of advocation of conventional therapeutics i.e.- potent antiemetic, antidiarrheal and rehydration ,usually associated with recurrence ,relapse and various post therapy consequent sequelae, but the present study reveals clinical supremacy of adjuvant Cytoprotective-local anaesthatic composite

SUCRALFATE-OXETACAIN combination in gel form can be exaplained as-

SUCRALFATE , a potent cyto protective coats the intestinal mucosa and prevent toxin or pathogen action over the intestinal mucosa and fails to alter the fluid and electrolyte transport system ,thus check increase in intestinal load ,hyper peristalsis and finally diarrhea frequency.

OXETACAINE (also known as oxethazaine), a potent local anesthetic produces local anesthesia ceases intestinal mucosal nerve endings and check tenesmus and abdominal colic.

Sucralfate also increases prostaglandin synthesis thus promote fluid and electrolyte transport from the intestine.

Cytoprotection of intestinal mucous membrane due to formation of a complex with mucosalprotein abstain the causative pathogen to invade the mucous membrane which check post therapy mucous colitis and urinary tract infection, in addition also restrict super infection. 
Due to coating of intestinal mucous membrane and inability to invade the mucous membrane the causative pathogen is exposed maximally to administered potent antibacterial and anti protozoal drug and virtually eliminate the causative pathogens.

Cytoprotective effect of the SUCRALFATE ensures natural healing to the underlying mucous membrane which restrict persistence of mucosal erosion.

\section{REFERENCE}

[1] SeifferJ; Glassman JM; Andyma GM ; Oxethazine and related congeners, a series of highly potent local anaesthatic, Am.Society of experimental biological medicine;109:664-668/1962

Citation: A. Shankar et al., "Sucralfate - Oxetacain Suspension in Management of Persistent Gastroenteritis of Varied Origin", International Journal of Clinical Chemistry and Laboratory Medicine (IJCCLM), vol. 3, no. 3, pp. 17-22, 2017. http://dx.doi.org/10.20431/2455-7153.0303004

Copyright: (1) 2017 Authors. This is an open-access article distributed under the terms of the Creative Commons Attribution License, which permits unrestricted use, distribution, and reproduction in any medium, provided the original author and source are credited. 